\title{
Ceramic material for fluoride and phosphate ions removal from natural water
}

\author{
O.G. Selivanov ${ }^{1}$, E.S. Pikalov ${ }^{2}$, A.S. Kolosova ${ }^{3}$ \\ ${ }^{1}$ Vladimir State University named after A. G. and N. G. Stoletovs, Vladimir, Russian Federation, \\ selivanov6003@mail.ru \\ ${ }^{2}$ Vladimir State University named after A. G. and N. G. Stoletovs, Vladimir, Russian Federation, \\ evgeniy-pikalov@mail.ru \\ ${ }^{3}$ Vladimir State University named after A. G. and N. G. Stoletovs, Vladimir, Russian Federation, \\ anastasiya_kolosova_777@mail.ru
}

\begin{abstract}
The research presents the development of ceramic material that can be used for fluoride and phosphate ions removal from natural water. The composition and the production technology of ceramic material containing lanthanum compound have been developed. Its physical and mechanical characteristics have been determined, and its binding capacity for fluoride and phosphate ions has been studied.
\end{abstract}

The process of fluoride and phosphate ions binding in the developed ceramic material is shown to occur because of ionicinteraction forces, where the ceramic material serves as a matrix with the fixed lanthanum ions with the increased chemical affinity for fluoride and phosphate ions. The microporous structure of the developed ceramic material facilitates ionic interaction of fluoride and phosphate ions with lanthanum ions throughout the entire material. The addition of 6 wt.\% lanthanum carbonate into the charge might help producing an effective ceramic material used for the natural water treatment containing up to $5 \mathrm{mg} / \mathrm{l}$ of phosphate ions and up to $13 \mathrm{mg} / \mathrm{l}$ of fluoride ions. Environmental safety of the material has been proved experimentally.

Key words: aqueous ecosystems, natural water, phosphate ions, fluoride ions, water treatment, ceramic material, lanthanum carbonate, environmental safety.

\section{INTRODUCTION}

Nowadays the growth of industrial production, intensive economic and recreational human activities cause significant pollution of surface and ground natural waters, balance disruption and natural water ecosystems oppression. Thus, the processes of aquatic ecosystems eutrophication have significantly increased, due to the intensive contamination of natural reservoirs with organic compounds and, in particular, nitrogen and phosphorus compounds contained in the agricultural enterprises waste water, which is discharged into reservoirs either poorly treated or as not authorized. A large number of phosphorus-containing compounds, which are synthetic detergents basis actively used by the population, enter natural reservoirs with household wastewater [1-3]. As a result, active water blooming occurs, blue-green algae over grows in natural and artificial water bodies. The resulting blue-green algae toxins significantly harm the inhabitants of the aquatic environment. Moreover the drastic change in species composition of water body microflora reduces in the number of useful and increases the number of potentially dangerous microorganisms, suppression of aqueous microbial and other types of selfpurification and water bodies accelerated degradation. Water from such reservoirs cannot be used as a source of drinking water supply .Similar tense situation is observed with underground natural waters. Their level has significantly decreased as a result of being used for drinking water source for the population and for technical needs supply. Water is welled from deeper horizons and is more highly mineralized. Such water might contain concentrations of certain cat ions or anions (for example, fluorine, manganese, strontium, etc.) above the established maximum permissible concentration regulations, thus threatening the public health if used as along term drinking water source. Thus, the increased concentration of fluoride ions in underground natural waters might cause such a disease as fluorosis human disease associated with fluoride intoxication. The residents of Moscow, Vladimir, Tver, Penza and Tambov regions are particularly susceptible to this disease, which is stipulated by both special chemical composition of underground water in these regions, associated with the natural factor of these geographical zones, their geochemical anomaly - excessive fluorine content in underground water sources in these territories, and considerable groundwater extraction for drinking water supply [4-5]. Some districts of the Vladimir region, such as Sobinka and Sudogda, where the population drinking water supply is from artesian wells, the increased content of fluoride in water is observed [6-7]. 
The excess fluorine removal is known to require complex purification methods: chemical, membrane, ion exchange, sorption [8-9], consequently modern defluorination systems are quite expensive water treatment facilities and to provide the population of all fluoroseendemic areas with the purified water without fluoride excess is rather complicated nowadays.

The research objective is to develop inexpensive ceramic material for the effective purification of natural water by removing both fluoride and phosphate ions.

\section{RESEARCH OBJECTS AND METHODS}

To produce the ceramic material, the clay from the Suvorotsky deposit in the Vladimir region of the following composition (wt.\%) was used: $\mathrm{SiO}_{2}=67.5 ; \mathrm{Al}_{2} \mathrm{O}_{3}=10.75$; $\mathrm{Fe}_{2} \mathrm{O}_{3}=5.85 ; \mathrm{CaO}=2.8 ; \mathrm{MgO}=1.7 ; \mathrm{K}_{2} \mathrm{O}=2.4 ; \mathrm{Na}_{2} \mathrm{O}=$ $0.7[8,9]$. The composition proves that the clay is characterized by low-plasticity, since it has a low content of $\mathrm{Al}_{2} \mathrm{O}_{3}$, so it is ineffective to use this clay in the construction industry as the main raw material for producing high-quality ceramic products. Such clay might be used for the production of construction ceramics only after its modification with various additives [10-12]. To expand the scope of its application, the authors proposed to use this clay for the ceramic material production modified with a lanthanum compound, to remove excess fluoride and phosphate ions from natural water. Lanthanum carbonate $\mathrm{La}_{2}\left(\mathrm{CO}_{3}\right)_{3}$ of $10-30$ microns particle size was used as lanthanum compound.

For the research the clay was pre-dried and ground dry in a ball mill, afterwards the max 30 microns particle size fraction was selected for the samples production. The selected fraction clay was thoroughly mixed with lanthanum carbonate in the proposed ratios reaching the homogeneous state. The ceramic material samples were made in the form of cubes with $50 \mathrm{~mm}$ side using the semi-dry pressing technology at the molding humidity of 8 wt. \% at the specific pressing pressure of $15 \mathrm{MPa}$ and firing temperature of $1050{ }^{\circ} \mathrm{C}[2]$.

After that, they were tested using standard methods for determining open porosity and compressive strength. Then the ceramic material samples were crushed into chips of 4-8 $\mathrm{mm}$ particle size of (Figure 1).

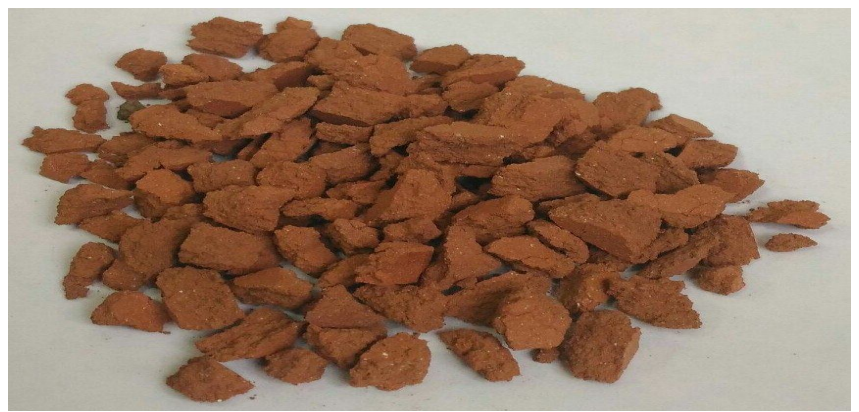

Figure 1. The sample of ceramic chips
The concentrations changes dynamics of fluoride and phosphate ions in aqueous model solutions in contact with the developed ceramic material was determined applying the capillary electrophoresis device "Kapel-104T". The resulting ceramic material toxicity was determined using the Daphnia magna Straus mortality method under the influence of toxic substances of the water extract from the studied ceramic samples, compared to the control culture in samples without toxic substances (control) [12].

\section{RESEARCH RESULTS AND THEIR DISCUSSION}

At the first research stage, the amount of lanthanum carbonate were manufactured and studied. The compositions and studied physical and mechanical properties of the samples are presented in table 1 .

Table 1: Charge compositions and physical-mechanical properties of ceramic material samples

\begin{tabular}{|c|c|c|c|c|}
\hline \multirow{2}{*}{$\begin{array}{c}\text { Compo- } \\
\text { sition }\end{array}$} & \multicolumn{2}{|c|}{$\begin{array}{c}\text { Charge composition } \\
\text { and components } \\
\text { amount, wt. \% }\end{array}$} & \multicolumn{2}{c|}{$\begin{array}{c}\text { Samples physical and } \\
\text { mechanical properties }\end{array}$} \\
\cline { 2 - 5 } & Clay & $\begin{array}{c}\text { Lanthanum } \\
\text { carbonate }\end{array}$ & $\begin{array}{c}\text { Porosity, } \\
\%\end{array}$ & $\begin{array}{c}\text { Compre } \\
\text { ssion } \\
\text { strength, } \\
\text { MPa }\end{array}$ \\
\hline 1 & 95 & - & 3.9 & 16.5 \\
\hline 2 & 91 & 4 & 4.3 & 15.3 \\
\hline 3 & 89 & 6 & 4.6 & 14.8 \\
\hline 4 & 87 & 8 & 5.0 & 14.2 \\
\hline
\end{tabular}

Table 1 demonstrated that the increase of lanthanum carbonate content in the charge causes slight decrease of the ceramic material compressive strength and the porosity increase which is explained by the lanthanum carbonate decomposition during firing at temperatures above $900 \mathrm{C}$ for lanthanum oxide and carbon dioxide, contributing to the porosity process. The strength characteristics maintaining is important for the regeneration and performance of the developed ceramic material chips, and the porosity increase contributes to efficiency improvement of the lanthanum containing material.

At the second stage, the effectiveness of fluoride and phosphate ions binding of the developed ceramic material containing lanthanum compound have been studied. The ceramic material samples were placed into the aqueous model solutions with certain concentrations of fluoride and phosphate ions. The experiments were carried out in the static mode during 15 days at 1:10 ratio of the ceramic material containing lanthanum carbonate and model solutions containing fluoride and phosphate ions. The model solutions sampling for the concentrations changes study of fluoride and phosphate ions was carried out in $1,5,10$, 15 and 20 days. 
The research results of changes in fluoride ions concentrations in aqueous model solutions depending on the contact time with the ceramic material are shown in figure 2.

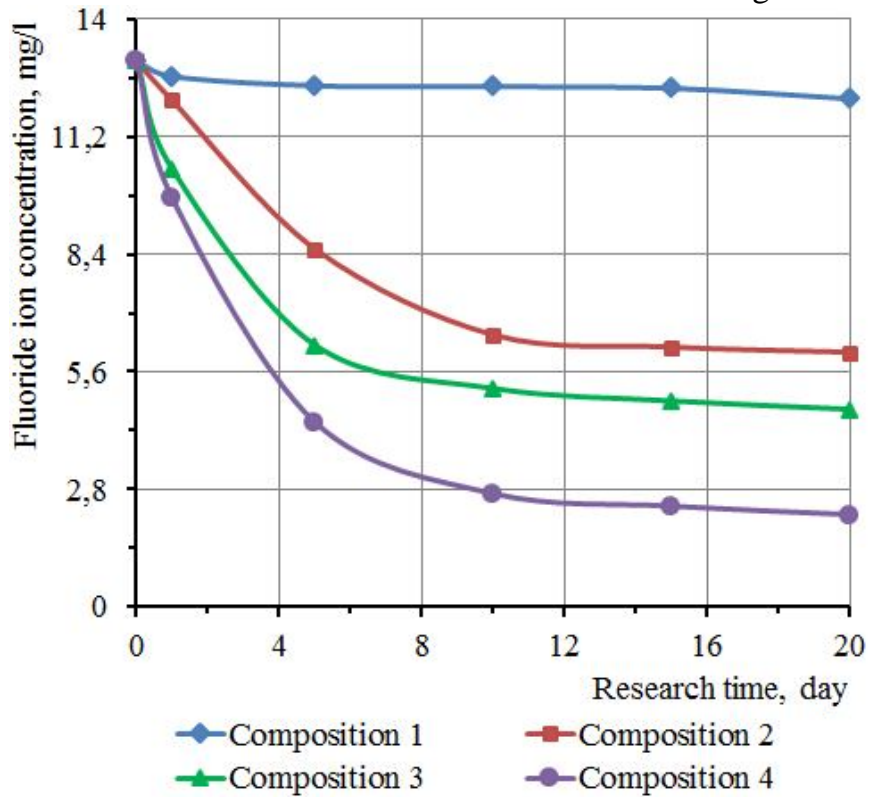

Figure 2: Changes of fluoride ion concentration in the model solution depending on the ceramic material composition and research time

Figure 2 shows that the samples obtained by the model solution contact with a ceramic material without lanthanum compounds (composition 1) reveal practically no change in the fluoride ions content, regardless contact time. Simultaneously alongside the increase of lanthanum carbonate content in the samples the ceramic material efficiency for binding fluoride ions also increases. The effective removal of fluoride ions from the model solution in 15 days occurred when using ceramic materials based on compositions 3 and 4 . The process of fluoride ions binding by the developed ceramic material occurs according to the ion exchange mechanism, where ceramic material with the fixed ions of trivalent lanthanum acts as a matrix, which can be represented as a poly-ion with the increased chemical affinity for fluoride ions. The ceramic material exchanges only counter-ions with the solution in the amount proportional to their chemical affinity for the poly-ion, while the fixed lanthanum ions remain in the solid ceramic phase. This circumstance allows considering the ceramic materialsolution system as a quasi-homogeneous volumetric chemical process based on the manifestation of ionic interaction forces and salvation forces.

Similarly, the ceramic material samples have been studied by being placed in aqueous model solutions of5 $\mathrm{mg} / \mathrm{l}$ phosphate ions concentration. The research results of changes in the phosphate ions concentrations of aqueous model solutions depending on the contact time with the ceramic material are shown in figure 3 .

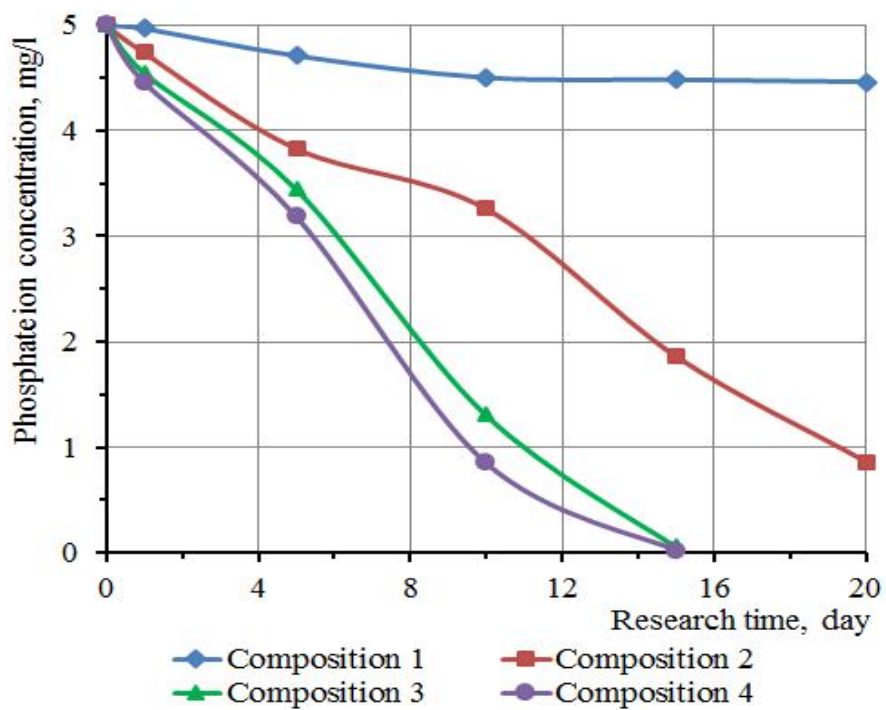

Figure 3: Changes ofphosphate ion concentration in the model solution depending on the ceramic material composition and research time

As figure 3 demonstrates the phosphate ions content in the model solution contacting the sample, made from the charge containing $4 \mathrm{wt}$. \%of lanthanum carbonate (composition 2)decreased by more than 2 times. Almost complete removal of phosphate ions purification from the model solution occurred during testing the samples made from the charge containing 6 and 8 wt. $\%$ of lanthanum carbonate (compositions 3 and 4).

At the third research stage the toxicity of the developed ceramic material samples has been determined. For this purpose, extracts from samples were prepared by leaching the crushed ceramic material by cultivation water in $1: 10$ ratio. The resulting mixture was stirred and exposed during 24 hours. Bio-testing was performed at $\mathrm{pH}=7.2-7.6$, the temperature of $20 \pm 2^{\circ} \mathrm{C}$ and $\min 6 \mathrm{mg} / \mathrm{dm}^{3}$ dissolved oxygen content. Each sample toxicity has been determined thrice.

The research results of the water extracts toxicity for the samples based on the studied compositions are shown in figure 4.

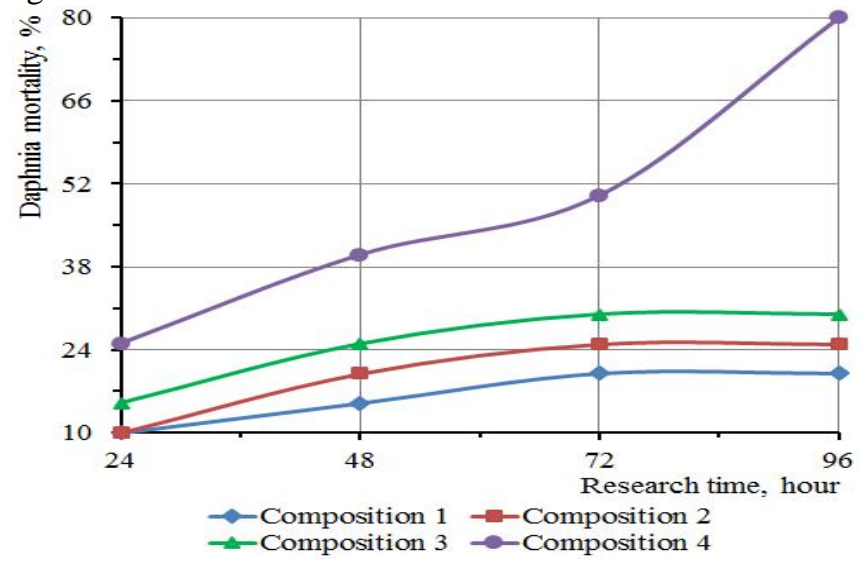

Figure 4: Daphnia mortality dynamics in aqueous extracts of different charge composition 
The study of the acute toxic effect of aqueous extracts from the developed ceramic materials samples for Daphnia magna Straus according to their mortality (acute toxicity criterion isover 50\% death of Daphnia during 96 hours) revealed that the composition 4 sample was characterized by the highest toxicity. The ceramic material samples from compositions 2-3 did not cause 50\% death of Daphnia during 96 exposure hours, thus indicating that these samples are not toxic and environmentally safe for living organisms.

\section{CONCLUSION}

According to the research results the developed ceramic material produced from the charge consisted of 89 wt. \% of clay, 6 wt. \% of lanthanum carbonate revealed the treatment efficiency for fluoride and phosphate ions removal from the aqueous model solutions creating the conditions for its application in real conditions for purifying water from natural drinking sources. The research has shown that the ceramic material is non-toxic and can be recommended as an environmentally friendly material.

\section{REFERENCES}

1. L. Kong, Y. Tian, Z. Pang, X. Huang, M. Li, R. Yang, N. $\mathrm{Li}$, J. Zhang, W. Zuo "Synchronous phosphate and fluoride removal from water by 3D rice-like lanthanumdoped La MgAl nanocomposites." Chemical Engineering Journal .2019, Vol. 371, pp. 893-902.

https://doi.org/10.1016/j.cej.2019.04.116

2. N.B. Singh, G. Nagpal, S. Agrawal, Rachna "Water purification by using Adsorbents: A Review." Environmental Technology \& Innovation . 2018, Vol. 11, pp. 187-240.

https://doi.org/10.1016/j.eti.2018.05.006

3. V.Yu. Chukhlanov, O.G. Selivanov, E.S. Pikalov, S.M. Chesnokova, A.A. Podolets "Purification of water from fluoride ions by a lanthanum-containing ceramic material." Ecology and Industry of Russia. 2018, Vol. 22, № 8, pp. 28-31.

4. J. Saikia, S. Sarmah, T. H. Ahmed, P.J. Kalita, R. L. Goswamee "Removal of toxic fluoride ion from water using low cost ceramic nodules prepared from some locally available raw materials of Assam, India." Journal of Environmental Chemical Engineering, 2017, Vol. 5, № 3, pp. 2488-2497.

5. T.A. Trifonova, A.A. Povorov, L.A. Shirkin, O.G. Selivanov, M.E. Ilina "Evaluating Membrane Separation Effectiveness for Highly Concentrated Aqueous Media Applying Two-stage Reverse Osmosis Plant." International Journal of Emerging Trends in Engineering Research. 2020, Vol.8, № 3, pp. 906-910.

https://doi.org/10.30534/ijeter/2020/47832020

6. N. Chen, Z. Zhang, C. Feng, M. Li, D. Zhu, R. Chen, N. Sugiura "An excellent fluoride sorption behavior of ceramic adsorbent." Journal of Hazardous Materials.2010, Vol. 183, № 1-3, pp. 460-465.

https://doi.org/10.1016/j.jhazmat.2010.07.046
7. T.A. Trifonova, A.A. Povorov, L.A. Shirkin, O.G. Selivanov, M.E. Ilina "Optimization of membrane reverse osmosis separation for aqueous media characterized by high mineralization." International Journal of Emerging Trends in Engineering Research. 2020, Vol.8, № 4, pp. 1125-1128.

https://doi.org/10.30534/ijeter/2020/47832020

8. V.N. Shakhova, A.V. Berezovskaya, E.S. Pikalov, O.G. Selivanov, É.P. Sysoev "Development of Self-Glazing Ceramic Facing Material Based on Low-Plasticity Clay." Glass and Ceramics. 2019, Vol. 76, № 1-2, pp. 11-15.

9. A.A. Vorob'eva, V.N. Shakhova, E.S. Pikalov, O.G. Selivanov, É.P. Sysoev, V.Yu. Chukhlanov "Production of Facing Ceramic with a Glazing Effect Based on LowPlastic Clay and Technogenic Waste from Vladimir Oblast." Glass and Ceramics. 2018, Vol. 75, № 1-2, pp. 5154.

10. A Kolosova, M. Sokolskaya, E. Pikalov, O. Selivanov "Production of facing ceramic material using cullet." E3S Web of Conferences. 2019, Vol. 91, 02003.

11. I.A. Vitkalova, A.S. Torlova, E.S. Pikalov, O.G. Selivanov "The use of polymer and glass waste to obtain a self-glazing facing ceramic." Ecology and Industry of Russia. 2019, Vol. 23, № 11, pp. 38-42.

https://doi.org/10.18412/1816-0395-2019-11-38-42

12. I. Vitkalova, A. Torlova, E. Pikalov, O. Selivanov "Energy Efficiency Improving of Construction Ceramics, Applying Polymer Waste." Advances in Intelligent Systems and Computing. 2019, Vol. 983, pp. 786794.

https://doi.org/10.1007/978-3-030-19868-8_77 